\title{
O movimento feminista no Brasil sob a ótica do Behaviorismo radical
}

\section{The feminist movement in Brazil under the perspective of radical behaviorism}

\author{
Luana Sousa dos Santos* \\ Mirella Hoschette Dearo Valverde* \\ Dra. Adriana Regina Rubio**
}

\begin{abstract}
Resumo
O presente estudo teve por objetivo analisar o movimento feminista no Brasil sob a ótica do Behaviorismo Radical. Observa-se que contingências de reforço mantidas por um grupo podem ser denominadas contingências culturais e caracterizam-se num nível de seleção pelas consequências - o nível de seleção cultural que fora proposto por F.Skinner a fim de compreender melhor o ser humano, completando as indagações que não podiam ser respondidas adequadamente pela seleção natural (ou filogenia) e a seleção operante (ontogenia). Assim, é possível compreender que o movimento feminista é uma prática cultural composta de metacontingências, em que há contingências entrelaçadas com recorrência envolvidas. Com estas concepções foi é possível analisar que o movimento feminista possibilitou mudanças nas práticas culturais do Brasil. Mudanças que envolvem diversas áreas de atuação da mulher: seja na esfera familiar, política e do mercado de trabalho.
\end{abstract}

Palavras-chave: movimento feminista, prática cultural, metacontingência, behaviorismo radical, Skinner.

* Psicólogas, graduadas pela Universidade Metodista de São Paulo

* Psicóloga, doutora em Psicologia pelo Depto. psicologia Experimental - Universidade de São Paulo - USP e docente da Escola Ciências Médicas da Universidade Metodista de São Paulo 


\begin{abstract}
The present study aimed to analyze the feminist movement in Brazil from the perspective of "Radical Behaviorism". It is observed that reinforcement contingencies maintained by a group can be denominated cultural contingencies and characterize a level of selection by the consequences - the level of cultural selection that had been proposed by F. Skinner in order to better understand the human being, completing the questions that could not be adequately answered by natural selection (or phylogeny) and operant selection (ontogeny). Thus, it is possible to understand that the feminist movement is a cultural practice composed of metacontingencies, in which there are intertwined contingencies with recurrence involved. With these conceptions it was possible to analyze that the feminist movement made possible changes in the cultural practices of Brazil. Changes that involve several areas of women's action: in the family, political and labor market.
\end{abstract}

Key words: feminist movement, cultural practice, metacontingence, radical behaviorism, Skinner

Em movimentos feministas, tanto no Brasil como em diferentes países e regiões, é sempre possível observar características culturais daqueles grupos ou comunidades. Por isso é possível denominar tais movimentos como "práticas culturais", ou contingências comportamentais entrelaçadas.

\title{
O movimento feminista como prática cultural
}

Para abordar sobre movimento feminista como prática cultural é necessário entender o que é a Cultura. Segundo o dicionário da língua portuguesa, de Ferreira (2010, p.213), a Cultura possui o seguinte conceito, entre outros: "o complexo dos padrões de comportamento, das crenças, das instituições, das manifestações artísticas, intelectuais, etc., transmitidos coletivamente, e típicos de uma sociedade".

A Antropologia e a Psicologia também exploram outros conceitos de Cultura. Laraia (1986/2006) analisa os estudos do antropólogo Alfred Kroeber, e afirma que a cultura é acumulativa e resulta da experiência histórica das gerações anteriores. Mais que uma herança genética, continua o autor, determina o comportamento do homem e 
justifica seus atos, pois este age de acordo com os padrões culturais a ele ensinados; desta forma, deduz-se que os instintos do homem foram parcialmente anulados no decorrer do longo processo evolutivo, dependendo ele mais do aprendizado do que das atitudes geneticamente determinadas para viver em sociedade.

Numa visão psicológica, Skinner (1953/2003) afirmara que cultura é aquilo que chamamos de ambiente social, sendo caracterizada pelas contingências de reforçamento social que geram e mantêm o comportamento dos membros de um determinado grupo. Normalmente, completa Moreira (2013), estas contingências vão além do tempo de vida dos membros e são constituídas de regras que formam as tradições e costumes de um grupo: o modo como estabelecem família, o vestuário de que se utilizam etc.

As contingências de reforço mantidas por um grupo são denominadas contingências culturais e caracterizam o terceiro nível de seleção pelas consequências - o nível de seleção cultural. Este nível foi proposto por Skinner $\left(1981 / 2007^{1}\right)$ a fim de compreender melhor o ser humano, completando as indagações que não podiam ser respondidas adequadamente pela seleção natural (ou filogenia) e a seleção operante (ontogenia).

O rápido desenvolvimento da cultura (ou das práticas culturais), ainda segundo Skinner (1981/2007), foi possível graças ao surgimento da linguagem, que permitiu a origem de ambientes sociais mais complexos através dos padrões comportamentais de cooperação, aconselhamento, formação de regras, aprendizagem por instrução e o desenvolvimento da consciência. ${ }^{2}$

No caso das práticas culturais, Moreira (2013) entende que essas são formadas por operantes ou conjuntos de operantes em contin-

Texto originalmente publicado na Revista Science, [Skinner, B.F. (1981). Selection by consequences. Science, 213, 501-504]. Esse se trata de tradução para a língua portuguesa feita pela Revista Brasileira de Terapia Comportamental e Cognitiva, sob licença da American Association for the Advancement of Science e pela B.F.Skinner Foundation.

2 Consciência e o operante verbal são considerados pelo Behaviorismo Radical aspectos diferenciadores do homem. Ambos são produto da seleção pela consequência, sendo o operante verbal a nível do condicionamento operante e a consciência, a nível da seleção de cultura. 
gências entrelaçadas. Deste modo, em um indivíduo, a reprodução e a variação de operantes estão relacionadas às consequências: os operantes repetem-se porque geram consequências reforçadoras em determinadas situações. $\mathrm{O}$ mesmo ocorre na reprodução de certas práticas culturais. Porém, ao abordar o nível da cultura, o conceito de reprodução está relacionado à transmissão e preservação de práticas para as gerações seguintes, ou seja, à transmissão de operantes entre os indivíduos de determinado povo.

As práticas culturais são compostas por contingências comportamentais entrelaçadas (GLENN, 2004). Estas, segundo Todorov (2015), diferenciam-se das contingências individuais, como expressões do tipo: "se..., então...", que descrevem relações entre eventos e são utilizadas como variável independente. Essas relações também são utilizadas no estudo experimental do comportamento em um grupo, porém a consequência é contingente ao produto da colaboração entre os indivíduos, não ao comportamento dos mesmos individualmente. Tal produto é parte do ambiente que identifica a ocorrência de contingências comportamentais entrelaçadas.

De acordo com Skinner (1953), as contingências entrelaçadas possuem consequências relevantes que são produzidas pelo comportamento operante de outro indivíduo. Trata-se, neste caso, da mediação de outro indivíduo. As contingências tríplices de dois ou mais indivíduos se sobrepõem ou se cruzam: a resposta, ou o produto gerado por esta, ou a consequência em uma das contingências participa como consequência em outra contingência. As consequências decorrentes de tal mediação podem ser: as próprias respostas operantes; consequências (reforços e punições) e resultados diretos destas respostas e consequências do outro.

Todorov (2015) complementa que as contingências comportamentais entrelaçadas (ou colaboração entre as pessoas) que ocasionam um produto agregado específico (resultado da colaboração), podem resultar em consequências selecionadoras. Ao abordar sobre fenômenos sociais que envolvem produtos agregados, as alterações ambientais produzidas pelo comportamento tornam-se o foco. Os comportamentos (contingências entrelaçadas) deixam de ser a variável a ser explicada e passam ser a variável que explica os produtos agregados. 
Partindo de tais definições é possível identificar no movimento feminista características que fazem de tal movimento uma prática cultural, pois as participantes do movimento, ao viverem no mesmo país e por estarem expostas aos mesmos estímulos advindos da Cultura e não aceitarem esta condição por ocasionar consequências punitivas, acabam por organizarem-se em grupo.

Independente dos estímulos responsáveis pela entrada das mesmas em tal movimento, as contingências entrelaçadas decorrentes da mediação das outras integrantes convergiram para uma consequência comum: o direito ao voto. Ou seja, as contingências individuais que motivaram a atuação no movimento deixam de ser o foco e as contingências entrelaçadas se tornam a variável que explica os produtos agregados.

O produto agregado trata-se do evento subseqüente à resposta e por ela produzido, conceito proposto para lidar com fenômenos sociais (GLENN, 2004). Ele é um resultado gerado pela resposta de mais de uma pessoa. Ou seja, a conquista do direito ao voto não seria possível se houvesse a intervenção de apenas uma mulher, sendo necessária a participação de várias para que a mesma se efetivasse.

Outro conceito importante que deve ser abordado ao falar sobre prática cultural é o de "metacontingência". Primeiramente, faz-se necessária a distinção entre a mesma e a "macrocontingência".

A metacontingência está para a análise da cultura assim como a contingência está para a unidade de análise do comportamento operante individual, é uma unidade de análise do terceiro nível de seleção: o Cultural. Conforme descreveu Glenn (2004), tem por função analisar a recorrência de contingências entrelaçadas e os produtos agregados destas, selecionados por uma consequência cultural.

Com relação à macrocontingência, esta descreve relações entre vários operantes recorrentes não entrelaçados que produzem um produto cumulativo que não retorna na manutenção dos operantes. Estes operantes envolvidos são mantidos por consequências individuais.

Assim, é possível compreender que o movimento feminista é uma prática cultural composta de metacontingências, em que há contingências entrelaçadas com recorrência envolvidas. As consequências reforçadoras (produtos agregados) geradas por estas 
contingências são responsáveis pela manutenção do movimento. As consequências decorrentes de macrocontingências, de acordo com Gleen (1986 apud TODOROV et al, 2005), em longo prazo, acabam por afetar o comportamento de toda uma sociedade.

Com base nesta definição, é possível analisar que o movimento feminista possibilitou e possibilita mudanças em práticas culturais que envolvem diversas áreas de atuação da mulher: seja na esfera familiar, política e mercado de trabalho.

Outro papel que o movimento desempenha é o de contra-controle às agências controladoras, tais como governo e religião. Segundo Skinner (1953/2003), o controle excessivo por parte do governo gera também comportamento da parte do controlado sob a forma de fuga, revolta ou resistência passiva. Exemplo de uma ação controladora excessiva é descrita por Westin e Sasse (2013) ao examinarem o Código Civil Brasileiro de 1916, em que as mulheres casadas eram consideradas incapazes e só tinham permissão para assinar contratos ou trabalhar fora de casa se tivessem a autorização do marido.

Segundo Skinner (1953/2003), na religião o comportamento não é visto apenas como "bom" e "mau", "legal" e "ilegal", mas sim como "moral" e "imoral". As consequências de ir para o Céu ou para o Inferno são tão ou mais poderosas do que aquelas de controle governamental. Porém, estes reforçadores ou punidores não operam durante toda a vida do indivíduo e dependem do quanto os reforçadores verbais são condicionados, principalmente a promessa do "Céu" ou "Inferno". Segundo Almeida (2012 a.), um exemplo de uma regra bíblica, que controla e justifica o comportamento da mulher está no livro de Efésios, capítulo 5 e versículos 22-24:

22. Vós, mulheres, sujeitai-vos a vossos maridos, como ao Senhor;

23. Porque o marido é a cabeça da mulher, como também Cristo é a cabeça da igreja, sendo ele próprio o salvador do corpo.

24. De sorte que, assim como a igreja está sujeita a Cristo, assim também as mulheres sejam em tudo sujeitas aos seus maridos.

Este controle, também excessivo, é questionado através do movimento feminista que busca direitos iguais para os sexos, modificando assim, em longo prazo, tal prática cultural. 
Outro tema, que tem penalidade prevista em lei e é considerada uma questão de saúde pública urgente pelo movimento feminista é a legalização do aborto. A Bíblia não trata especificamente, mas os movimentos em prol da família se utilizam de passagens bíblicas para dificultarem a criação de leis que o legalizem como prática de saúde pública, e que segundo Almeida (2012 b.) constam, por exemplo, no livro de Jeremias 1:5: "Antes que eu te formasse no ventre materno, eu te conheci, e, antes que saísses da madre, te consagrei, e te constituí profeta às nações." ; Êxodo, capítulo 20 e versículo 3: "Não matarás"; além do capítulo 21, versículos 22 e 23, do mesmo livro:

22. Se alguns homens pelejarem, e um ferir uma mulher grávida, e for causa de que aborte, porém não havendo outro dano, certamente será multado, conforme o que lhe impuser o marido da mulher, e julgarem os juízes.

23. Mas se houver morte, então darás vida por vida

A penalidade para tal prática (aborto) consta no Código Penal, compreendida entre os artigos 123 a 126, podendo a pena variar de 1 até 10 anos. Não aprofundaremos o assunto no presente trabalho, mas alguns apontamentos tornam-se necessários, pois o aborto é a terceira causa da morte materna no Brasil, segundo pesquisa do Ipas Brasil (GALLI; VIANA; SHIRAIWA, 2010). De acordo com Vianna (2012), ainda que o aborto seja uma prática ilegal é realizado por mulheres de todos os níveis socioeconômicos, Reside a diferença no fato de que as de possuem melhores condições econômicas pagam por procedimentos mais seguros, enquanto as pobres utilizam-se de métodos auto abortivos sem acompanhamento, curetagem ou sucção em clínicas clandestinas, que ocasionam diversas mortes. Assim, continua o mesmo autor, o "debate sobre a descriminalização do aborto não é sobre o direito ou não de a gestante abortar, mas sobre o direito ou não de a gestante ter auxílio médico para abortar" . Mas, a Constituição brasileira garante (artigo 226, §7º ), que "o planejamento familiar é livre decisão do casal, competindo ao Estado propiciar recursos educacionais e científicos para o exercício desse direito, vedada qualquer forma coercitiva por parte de instituições oficiais ou privadas . 
Logo, tendo o movimento feminista por pauta este tema e buscando descriminalizá-lo e legalizá-lo, de forma que o Sistema Único de Saúde (SUS) forneça atendimento seguro e acompanhe o pós-aborto, garantindo a integridade física e psicológica da mulher, novamente é possível identificá-lo como um movimento que tem por papel o contracontrole às agências governamentais e religiosas.

A feminista e filósofa Simone de Beauvoir, em seu livro "O segundo sexo: A experiência vivida", diz que:

Nenhum destino biológico, psíquico, econômico define a forma que a fêmea humana assume no seio da sociedade; é o conjunto da civilização, que elabora esse produto intermediário entre o macho e o castrado que qualificam de feminino. Somente a mediação de outrem pode constituir um indivíduo como um Outro (BEAUVOIR, 1967, p. 09).

Destarte, a filósofa explicita que o conceito "ser mulher" é construído socialmente, ou em outras palavras, é um conceito que foi reforçado ao longo dos anos, tornando-se uma prática cultural: há comportamentos ditos femininos que são reforçados por determinado grupo, mas não o são para as mulheres que nele estão, pois privam-nas da autonomia e liberdade tanto pessoal quanto profissional.

O movimento feminista questiona o papel imposto à mulher, justificado socialmente por seu gênero. A distinção entre sexo e gênero, proposta por Simone de Beauvoir (1967) baseia-se nos seguintes conceitos: o sexo seria biológico (caracterizado pelas diferenças biofisioanatômicas entre machos e fêmeas), enquanto o gênero seria aquele socialmente construído (caracterizado pelos papéis dados aos homens e às mulheres, como estereótipos de masculinidade e de feminilidade - como é possível ler no trecho acima extraído do livro: “O segundo sexo: A experiência vivida").

O corpo e as ações das mulheres só assumem um papel feminino (como fragilidade, por exemplo) dentro de um contexto social, que é baseado em padrões. A desigualdade entre homens e mulheres no mundo não possui fundamentos biológicos, mas é construída, mantida e justificada através das práticas culturais Beauvoir (1970 apud SILVA; LAURENTI, 2016). 
Ainda sobre a discussão do lugar que é destinado à mulher, pelo simples fato de nascer do sexo feminino, Silva e Laurenti (2016) concluem em seu trabalho que a visão de ser humano baseado no modelo de seleção pelas consequências proposto por Skinner é compatível com a tese de que não há uma essência feminina, logo o papel que a mulher desempenha na sociedade é determinado por práticas culturais e não pelo sexo biológico, refutando-se comportamentos considerados naturalmente femininos, como a vocação aos trabalhos domésticos, falta de habilidade na participação política, discrepância salarial entre homens e mulheres, entre outros.

Nota-se, a partir do exposto, a importância da discussão sobre gêneros, também uma das reivindicações do movimento feminista. Pois, além de difundir as desigualdades já citadas, a ideologia de gênero contribui para a violência contra a mulher e até mesmo ao feminicídio, já que o homem é tido socialmente como superior.

Devido às desigualdades presentes na sociedade brasileira, que são respaldadas tanto pela lei, quanto pela religião e pelo senso comum, e que são reforçadas pelas práticas culturais vigentes, o movimento feminista faz-se necessário e mantêm-se, pois os estímulos fornecidos pelo ambiente social são aversivos e punitivos, levando muitas mulheres a participarem do movimento. As metacontingências envolvidas são diversas e o produto agregado garante a igualdade de direitos defasada, mesmo tratando-se o século XXI. São dois séculos de luta, que continuará existindo até que as práticas culturais modifiquem-se e garantam à mulher o papel social que ela queira ocupar, desprovido de estereótipos de gênero sem qualquer embasamento científico.

\section{Contingências mantenedoras do movimento feminista}

O movimento organizado e intitulado "feminista", iniciou sua primeira onda no Brasil em 1917, caracterizado pelo movimento da "União das Costureiras, chapeleiras e Classes anexas”, que reivindicava melhores condições de trabalho, qualidade de vida, salário e respeito (PINTO, 2003 apud Pinto, 2010). Porém, desde o séc. XIX houve intervenções responsáveis pelo início da conquista dos direitos femininos, como a implantação da legislação que autorizava a 
abertura de escolas femininas em 1827, além de livros traduzidos ou de autoria de escritoras brasileiras, que acabaram por possibilitar a criação de tal movimento no século XX (DUARTE, 2003).

É possível identificar as contingências que propiciaram a implantação do movimento feminista na época e que são caracterizadas pelo controle excessivo exercido pelas agências de controle, principalmente o governo, no que tange aos direitos das mulheres. Segundo Skinner (1953/2003), certos sub-produtos do controle exercido pelo grupo e agências de controle são prejudiciais tanto para o indivíduo como para o grupo, principalmente se este controle torna-se excessivo. Os subprodutos podem ser a fuga, a revolta e a resistência passiva.

Embora nem a Constituição Imperial de 1824, como a primeira Constituição Republicana de 1891, proibissem o direito de votar às mulheres, ao mesmo tempo não lhes outorgara, em termos claros e precisos. Diversas polêmicas ocorreram ainda na Velha República, entre políticos e júris consultos quanto a envolver as mulheres no vocábulo "cidadãos" constante da Carta Magna de 1891, a qual trazia ao final do texto: "são eleitores os cidadãos maiores de 21 anos que se alistarem na forma da lei" (BRASIL, 1891).

Tal controle excessivo culminou no subproduto de revolta (contracontrole) por parte das mulheres em 1918, quando o Partido Republicano Feminista mobilizou-se pela luta do sufrágio (COSTA, 2005) e, em 1927, a Federação Brasileira pelo Progresso Feminino, criada por Bertha Lutz, enviou o abaixo-assinado ao Senado, solicitando a aprovação do projeto de Lei que especificava o direito de voto das mulheres (PINTO, 2010). Tal direito foi aprovado em 1927 no Rio Grande do Norte, porém outros estados não seguiram o exemplo.

Ainda conforme Pinto (2010), conquistado o direito do voto, as mulheres têm o poder de decidir o futuro da política e de eleger mulheres para representá-las, como de fato ocorreu em 1929, quando Alzira Soriano foi eleita prefeita no Rio Grande do Norte.

De acordo com Glenn (2004), a metacontingência ocorre com o entrelaçamento de contingências comportamentais entrelaçadas (CCEs) e seus produtos agregados (PAs). Estes entrelaçamentos tornam-se recorrentes e produzem efeitos ambientais (produtos agregados) aos quais são contingentes consequências selecionadoras 
Logo, a conquista do voto só foi possível graças ao número de mulheres envolvidas num processo em que colaboraram umas com as outras, seja participando do abaixo-assinado, seja em manifestações (contingências entrelaçadas), e cujos comportamentos culminaram no direito ao voto (produto agregado), produzindo a consequência cultural, caracterizada pela representatividade feminina na política e criação de leis que modificaram, de certa forma, o papel da mulher na sociedade.

Evidencia-se, pois, as contingências que favoreceram o nascimento do movimento feminista no Brasil e que o mantiveram inicialmente, mudando as práticas sociais relacionadas à mulher no século XX. Mesmo com as mudanças nas práticas culturais, ou seja, no papel que a mulher ocupava e como era vista pelos demais membros do grupo, ainda permaneceram outras práticas tidas como normais, que eram controladas ou punidas através da lei.

O longo prazo para a implementação efetiva do direito do voto feminino é exemplo de permanência de prática cultural punitiva, pois, ainda que o voto tenha sido aprovado no Rio Grande do Norte em 1927, de acordo com Duarte (2003), foi apenas em 1932 que Getúlio Vargas cedeu aos apelos do movimento e concedeu a mulher o direito de votar com as mesmas condições que os homens, com exceção dos analfabetos. A eleições foram suspensas e as mulheres votaram oficialmente pela primeira vez nas eleições de 1945.

A violência contra a mulher é outra prática cultural ainda presente em nossa sociedade, apesar da instituição da lei Maria da Penha (BRASIL, 2006), em cujo teor está a coibição e punição para atos de violência contra mulheres. A continuidade das práticas que subjugam as mulheres em suas funções e papéis, ocorre por se tratar de um comportamento social que, de acordo com Skinner (1953/2003), tem suas consequências mediadas pelo outro indivíduo, que pode reforçá-las ou não. Outra causa possível é o fato de a lei tratar-se de uma metacontingência e sua consequência ocorre em longo prazo; de forma que enquanto não se incorporar a própria lei e os comportamentos não violentos como uma prática cultural, a violência permanecerá ocorrendo (explica-se o porquê da discrepância de tempo entre o direito do voto e o ato de votar das mulheres). 
Observam-se então, que diversas metacontingências colaboraram e colaboram para a manutenção do movimento feminista, o qual evoluiu e modificou suas reivindicações, pois busca atender às lacunas ainda existentes no que se refere à prática efetiva dos direitos da mulher. Desta forma, as pautas feministas não são estáticas, mas se transformam a fim de se oporem às práticas culturais arraigadas que prejudicam as mulheres; práticas estas baseadas em preconceitos e argumentos ilógicos reforçados pela Cultura e respaldadas (controladas) pelo governo, religião e educação - as três agências citadas por Skinner (1953/2003) e que são responsáveis pelo controle.

Contingências tais como violência, por exemplo, levaram o Estado, nos anos oitenta do século passado, à criação da Delegacia de Polícia de Defesa da Mulher (SÃO PAULO, 1985). Tal decreto surgira a partir de projeto formulado pelo Prof. Michel Temer (atual presidente da República do Brasil), com intuito de realizar atendimentos específicos e mais humanizados, além ações de prevenção, proteção e investigação dos crimes de violência doméstica e violência sexual contra as mulheres, entre outros. Consecutivamente, outros estados da nação aderiram à proposta e criaram suas delegacias.

Assim, aliado à não aceitação do controle, o movimento é reforçado pelas consequências que garantem cada vez mais sua igualdade, conquistada através das mudanças na legislação (produtos agregados) e o mesmo modifica-se a depender da legislação vigente (agência controladora) e da prática cultural.

Como exemplo de produtos agregados que vêm gerando consequências reforçadoras em longo prazo para as mulheres, é possível citar a lei federal do feminicídio (BRASIL, 2015). Nela, o feminicídio é considerado uma modalidade de homicídio qualificado, entrando, portanto, no rol dos crimes hediondos.

Esta lei tem por objetivo combater a prática de homicídio contra a mulher e que, segundo Botelho (2013) o próprio o Instituto Avante Brasil anuncia que há uma morte a cada hora, sendo metade destes homicídios dolosos praticados em violência doméstica ou familiar. Desta forma, a consequência resulta na seguridade da mulher respaldada pela lei, dando a esta o direito de viver.

Porém, ainda há várias práticas culturais que ferem os direitos de igualdade e exaurem o poder da mesma de decisão sobre o 
próprio corpo. Estas práticas são alvo da luta feminista, que busca mudança através da legislação e educação: É possível citar algumas, como a criminalização do aborto respaldada pela lei; a desigualdade salarial no desempenho da mesma função; jornada dupla, como se fosse obrigação da mulher cuidar dos afazeres domésticos, culpabilização da vítima em caso de assédio ou estupro, proibição da discussão de gênero nas escolas, dentre uma gama variada de outras práticas.

Estas contingências manterão a ocorrência do fenômeno movimento feminista, pois a legislação, no papel do governo, atua como agência controladora, advindo o contracontrole por parte do movimento. Este contracontrole culmina em consequências que modificam práticas sociais e o comportamento dos membros do grupo, como exposto por Carrara (2008) a seguir

[...] as conseqüências que agem sobre o indivíduo selecionam suas respostas particulares; já as conseqüências que atuam sobre os membros de um grupo enquanto tal selecionam práticas culturais que, em última análise, também remetem aos comportamentos dos indivíduos, mas com uma especificidade distintiva: são tipicamente comportamentos articulados responsáveis pela produção de conseqüências compartilhadas pelos membros do grupo (p. 49).

\section{Considerações finais}

O presente texto buscou fazer apontamentos sobre o movimento feminista como uma prática cultural, formada por metacontingências, ou seja, as participantes colaboram umas com as outras, produzindo o produto agregado, como a mudança na legislação que garante o direito das mulheres e a Lei do Feminicídio, por exemplo. As consequências relevantes para a sociedade selecionam os comportamentos dos indivíduos de forma que acontecem as mudanças (menor índice de morte de mulheres, tendo por base o exemplo citado).

Concluiu-se que feminista existirá enquanto houver contingências que o propiciem e enquanto lutar pelos direitos se fizer necessário. As mulheres conseguiram vencer sua invisibilidade na sociedade e conquistaram seu espaço na política, no trabalho e no 
âmbito social e cultural, visto que estudam em escolas e instituições de ensino superior, atuam no mercado de trabalho, ocupam cargos de alto poder e confiança, realizam um controle familiar através de métodos anticoncepcionais e decidem sobre o seu corpo e o que querem para si (se querem ou não constituir uma família, ter filhos ou não). Há também mulheres que mantêm uma relação de respeito com homens ao invés de submissão, e a presença feminina na política, chegando ao auge com a eleição da presidente Dilma Vana Rousseff em outubro de 2010.

Diante dessas mudanças e espaços já alcançados, constatou-se mediante a pesquisa e o trabalho realizado que ainda há muitos direitos a serem conquistados e efetivados, tais como: equidade de salário entre os sexos que exercem a mesma função; transitar livremente por vias públicas, particulares e utilizar de transportes públicos sem sofrer violência ou assédio, independente do horário; ser ouvida e levada em consideração sobre seus pontos de vista e experiência sem que seja diminuída ou desvalorizada; decidir sobre seu corpo; ser tratada como ser humano e não como objeto, etc. Um direito primordial que merece destaque é a garantia da vida, já que a porcentagem e frequência com que mulheres sofrem violências sexuais, físicas e emocionais são estarrecedoras.

Uma forma eficaz de modificar as práticas sociais que mantêm a mulher em posição de desigualdade é estabelecer o debate sobre gênero nas escolas, de forma que as crianças aprendam novas possibilidades de atuação para as mulheres na sociedade, não restringindo seu papel baseado numa ideia conservadora e ilógica, mas evidenciando que a mulher pode ocupar lugares antes reservados apenas aos homens.

\section{Referências}

ALMEIDA, J. F. Bíblia online João F. Almeida Atualizada. [S.I.], 2012 a.

Disponível em: <http://biblia.com.br/joao-ferreira-almeida-atualizada/efesios/ef-capitulo-5/> Acesso em: 25 mar. 2016.

ALMEIDA, J. F. Bíblia online João F. Almeida Atualizada. [S.I.], 2012 b.

Disponível em: http://biblia.com.br/joaoferreiraalmeidarevistaatualizada/exodo/ ex-capitulo-20/Acesso em: 19 out. 2016. 
ALMEIDA, J. F. Bíblia online João F. Almeida Atualizada. [S.I.], 2012. Disponível em: $<$ http://biblia.com.br/joaoferreiraalmeidarevistaatualizada/jeremias/jr-capitulo-1/> Acesso em: 19 out. 2016.

ALMEIDA, J. F. Bíblia online João F. Almeida Atualizada. [S.I.], 2012. Disponível em: <http://biblia.com.br/joao-ferreira-almeida-corrigida-revisada-fiel/exodo/ex-capitulo-21/> Acesso em: 19 out. 2016.

BEAUVOIR, S. O segundo sexo: a experiência vivida. São Paulo: Difusão européia do livro, 1967.

BOTELHO, F. M. Homicídios de mulheres no Brasil em 2013. Instituto Avante Brasil, 2013. Disponível em: <http://d2kefwu52uvymq.cloudfront.net/uploads/2015/10/ Levantamento-genero.pdf $>$ Acesso em: 19 nov. 2016.

BRASIL. Constituição da República dos Estados Unidos do Brasil. Rio de Janeiro, 1891. Disponível em: <http://www.planalto.gov.br/ccivil_03/Constituicao/Constituicao91. htm> Acesso em: 19 nov. 2016.

BRASIL, Lei n. 11.340 de 07 de agosto de 2006. Lei Maria da Penha. Brasília, DF, 2006. Disponível em: <https://www.planalto.gov.br/ccivil_03/_Ato2004-2006/2006/ Lei/L11340.htm> Acesso em: 19 nov. 2016.

BRASIL, Lei n. 13.104, de 9 de março de 2015. Lei do Feminicídio. Brasília, DF, 2015. Disponível em:<http://www.planalto.gov.br/ccivil_03/_Ato2015-2018/2015/lei/L13104. htm> Acesso em: 19 nov. 2016.

CARRARA, K. Entre a utopia e o cotidiano: uma análise de estratégias viáveis nos delineamentos culturais. Revista Psicolog. Ribeirão Preto, SP - Brasil. vol. $1 \mathrm{n}$. 1. p. $42-54,2008$.

COSTA, A. A. A. O movimento Feminista no Brasil: Dinâmicas de uma Intervenção Política.Set., 2005. Disponível em: http://www.revistagenero.uff.br/index.php/ revistagenero/article/viewFile/380/285>Acesso em: 28 fev. 2016.

DEBELAK, C.; DIAS, L.; GARCIA, M. Feminicídio no Brasil: A cultura de matar mulheres. Disponível em: < http://feminicidionobrasil.com.br/> Acesso em 01 maio 2016.

DUARTE, C. L. Feminismo e Literatura no Brasil. Estud. Avançados., São Paulo , v. 17, n. 49, p. 151-172, Dec. 2003 . Disponível em: http://www.scielo.br/scielo. php?script=sci_arttext\&pid=S0103-40142003000300010\&lng=en\&nrm=iso .Acesso em: 28 mar. 2016.

FERREIRA, A. B. H. Mini Aurélio: o dicionário da língua portuguesa. Curitiba: Positivo, 2010. 
GALLI, M. B.; VIANA, P.; SHIRAIWA, T. Dossiê A realidade do aborto inseguro: o impacto da ilegalidade do abortamento na saúde das mulheres e na qualidade da atenção à saúde reprodutiva no estado do Rio de Janeiro. Rio de Janeiro: Ipas, 2010. Disponível em: http://www.observatoriodegenero.gov.br/menu/publicacoes/outros-artigos-e-publicacoes/dossie-a-realidade-do-aborto-inseguro-o-impacto-da-ilegalidade-do-abortamento-na-saude-das-mulheres-e-nos-servicos-de-saude-do-estado-do-rio-de-janeiro/view. Acesso em 19 out. 2016.

GLENN, S. S. Individual Behavior, Culture, and Social Change. The Behavior Analyst, v. 27, n.2,:p. 133-151, 2004.

LARAIA, R. B. Cultura: Um conceito antropológico. Rio de Janeiro: Jorge Zahar Editora, 2006. (original de 1986)

LISBOA, T. K. Gênero, feminismo e serviço social - encontros e desencontros ao longo da história da profissão. Revista. Katál. Florianópolis v.13, n.1, p. 66-75, jun 2010

MOREIRA, M. B.; MACHADO, V. S.; TODOROV, J. C. Cultura e Práticas Culturais. In: MOREIRA, M. B. (Org.) Comportamento e práticas culturais. Brasília: Instituto Walden4, (p. 14-23), 2013.

PINTO, C. R. J. Feminismo, História e Poder. Revista Sociol. Polit., Curitiba, v. 18, n. 36, p. 15-23, Junho 2010. Disponível em http://www.scielo.br/pdf/rsocp/v18n36/03. pdf Acesso em: 10 mar. 2016.

SÃO PAULO. Decreto no 23.769, de 6 de agosto de 1985. São Paulo, 1985. Disponível em:<http://governo-sp.jusbrasil.com.br/legislacao/194816/decreto-23769-85>Acesso em: 19 nov. 2016.

SKINNER, B.F. Ciência e comportamento humano. São Paulo: Martins Fontes, 2003 (original de 1953).

SKINNER, B. F. Seleção por consequências. Revista Brasileira de Terapia Comportamental e Cognitiva. [S.I], v. 9, n.1, p. 129-137, 2007. Disponível em: <http://www. usp.br/rbtcc/index.php/RBTCC/article/view/150/133>. Acesso em: 24 mar. 2016.

TODOROV, J.C. Contingências comportamentais entrelaçadas são partes subentendidas da relação condicional na metacontingência. 2015. Disponível em: <http://jctodorov. blogspot.com/2015/06/contingencias-comportamentais.html>. Acesso em 19 out. 2016.

TODOROV, J.C.; MARTONE, R.C.; MOREIRA, M.B. Metacontingências: comportamento, cultura e sociedade. Santo André: Esetec, 2005.

VALEK, A. O que as feministas defendem? Carta Capital. 16 jul. 2014 Escritório Feminista. Disponível em: <http://www.cartacapital.com.br/blogs/escritorio-feminista/o-que-as-feministas-defendem-3986.html> Acesso em: 24 nov. 2016 
VIANNA, T. Legalizar o aborto. Disponível em: <http://www.revistaforum.com. br/2012/02/09/legalizar-o-aborto/>. Acesso em 20 out. 2016.

WESTIN, R.; SASSE, C. Na época do Brasil colonial, lei permitia que marido assassinasse a própria mulher. Jornal do Senado. Brasília, 07 jul. 2013. Disponível em: <https://www12.senado.gov.br/jornal/edicoes/especiais/2013/07/04/na-epoca-do-brasil-colonial-lei-permitia-que-marido-assassinasse-a-propria-mulher $>$. Acesso em 24 mar. 2016.

SILVA, E. C.; LAURENTI, C. B. F. Skinner e Simone de Beauvoir: "A mulher" à luz do modelo de seleção pelas consequências. Perspectivas em Análise do Comportamento. Paraná, v. 7, n. 2, p. 197-211, out., 2016. Disponível em: <https://www. revistaperspectivas.org/perspectivas/article/view/185/169>. Acesso em: 15 nov. 2018.

\section{Contato dos autores:}

Luana Santos: luanasousantos@gmail.com

Texto Recebido em 10/09/2017

Aceito em 02/12/2017 